\title{
CORRESPONDENCE
}

\section{QUININE AMBLYOPIA}

To the Editors of THE BRITISH JouRnal OF Ophthalmology.

DEAR SIRS,-In the descriptions given of quinine amblyopia, it is stated that the disc is pale and the vessels greatly constricted. In this connection, an interesting case came under observation in Changi P.O.W. camp. The patient, Sapper W., of the Royal Engineers, was in hospital with jaundice when he developed malaria. He had previously been under observation for his eyes with conjunctivitis and (? ?) retrobulbar neuritis, due to deficiency disease, but had not been under treatment for it. (He came under my observation first on July 12, 1945).

On July 10, 1945, when his M.T. malaria developed, he was put on quinine, grains 30 , daily, for seven days, this being the usual treatment.

On July 11,1945 , he developed very severe headache and also became restless. He was given aspirin, grains 10 . During the afternoon he developed tinnitus, and about 5.30 p.m. complete loss of vision with pupils widely dilated.

He was not seen by me until next day at about 11 a.m. When I examined him he had complete amaurosis. His pupils were widely dilated, inactive to light and accommodation. Hippus was present, the media were clear, and the fundi appeared normal. The vessels were of normal calibre. General examination showed no cerebral changes; central nervous system N.A.D.; blood pressure 90/52.

He was given two capsules of amyl nitrite to inhale-acetylcholine was not available in the camp. In the afternoon about 3 o'clock, the patient reported that there was some return of vision, particularly in the right eye. He stated that everything appeared to be blue. Fields were constricted to tube vision.

On July 13, 1945, vision still improving, still blue, and the patient complained of photophobia.

I did not examine him again thoroughly until July 21, 1945. Visual acuity, hand movements only, everything still appeared blue, fields very constricted. He could not distinguish the Ishihara vision charts. Stated that the demonstration chart (red 12 on blue background) appeared as blue figures on a blue circle on light blue background. Examination of fundi showed discs normal, but arteries very constricted and veins reduced in calibre. The arteries left the disc more or less normally, and then tapered away rapidly to mere threads. Otherwise nothing abnormal in the fundi.

On July 24, 1945, pupils were active to light, the blue vision was 
still present, and the fundi showed the vessels still, very constricted.

On August 19, 1945, his vision had mùch improved, he could read slowly J.8. His vision was still somewhat blue. The fundi showed the vessels to be much more prominent and the fields fairly full to hand movements.

On September 6, 1945, vision much improved. Blue vision had disappeared, but he noticed what he described as blackness in the later afternoon and at night.

Examination of the eyes showed the discs normal, vessels still much constricted, especially the arteries, and the fields showed peripheral constriction.

He was not seen again after this by me, as we had been relieved by the incoming forces.

I was informed that about 40,000 patients had received treatment for malaria, either primary or relapses, in the camp during our period as P's.O.W. This was the only case of quinine amblyopia which occurred.

I think it is interesting to note that the fundi were normal and vessels normal in calibre 48 hours after the onset of the complete blindness, and only later did the constriction appear, also that the discs appeared normal throughout.

I wish to thank the Director-General of Medical Services, for permission to publish this case.

8. Collins Street,

Yours faithfully,

R. Grarme OrR.

Melbourne.

September 25, 1946.

\section{GRADES OF VISION}

To the Editors of THE BRITISH JOURNAL OF OPHThalmology.

DEAR SIRS,-Having read the article by $\mathrm{Mr}$. Joseph Minton, and noted the suggested grades of vision, I was wondering if the problem of amblyopia in returned P's.O.W. had been considered at all. Observation of, and discussion with, many of them has suggested to me that the disability for certain occupations may be much beyond what is suggested by the ordinary test for visual acuity.

To begin with the standard of $6 / 6$ is for many people, a low one ; many can easily attain $6 / 5$ and $6 / 4$. Consequently, those who have been reduced from $6 / 4$ to $6 / 6$ or $6 / 9$ by disease are at a disad vantage.

When the lowered visual acuity is caused not by refractive errors 